\title{
SIMULATION AND HARDWARE IMPLEMENTATION OF CHANGE IN CONDUCTANCE MPPT CONTROLLER FOR A SOLAR PHOTO VOLTAIC SYSTEM USING CUK CONVERTER
}

\author{
Raju .D ${ }^{1}$, S.Ranga Rajan ${ }^{2}$ \\ Auroras Engineering College.Bhongir, Andhra Pradesh \\ dharavath.232@gmail.com,dharavath_raju@yahoo.co.in,srenga_49@yahoo.com
}

\begin{abstract}
This paper presents simulation implementation of incremental conductance maximum power point tracking (MPPT) used in solar array power system. The comparative study between two most popular algorithms techniques Which is incremental conductance Algorithm and perturbs and observe algorithm two different converter cuk and buck converter used for comparative in this study few comparison such as voltage, current and power out for each different combination has been recorded? The resultant system is capable of tracking MPPS accurately and rapidly without steady state oscillation and also its dynamic performance is satisfactory. The main different of the proposed system to existing MPPT system is eliminating the PI (proportional integral) control loop and investigating the effect simplifying the control circuit.MAT LAB/Simulink were employed for simulation studies and CCStudiov3.1 was used to program a TMS320F2812DSP.The propose system was developed and tested successfully in laboratory on the PV solar panel. Experimental result indicates the feasibility and improved functionality of the system.
\end{abstract}

Keywords: PV Systems; Maximum power point Tracking (MPPT); Incremental Conductance (IncCond); Digital Signal Processor (DSP).

\section{INTRODUCTION}

Now a day increase in the demand for electricity and the rapid change in the environmental condition such as global warming led to a need for a new source of energy that is cheaper and clean efficient and sustainable with less corbon emissions out of all the available renewable energy source solar power system attract more attention, because they provide excellent opportunity to generate electricity while green house emission are reduced. It is also provided gratifying to lose reliance on conventional electricity generated by natural gas, hydel, nuclear and burning coal.

Solar energy has offered promising resulting in the quest of finding the solution to the problem .the harnessing of solar energy using PV modules comes with its own problems that arise from the change in insulation condition panel due to fast climate changes such as cloudy weather and increasing in ambient temperature can reduce the Photo voltaic (PV) array output power.

So the poor efficiency of PV system some method are proposed, amongst which is a new concept is called as Maximum Power Point Tracking (MPPT) is introduced. This research then loops at how a different type of converter effects the output power of the module and also investigate if the
MPPT that are said to be highly efficient and do track the true maximum power point under the various conductance.

\section{A).MPPT Methods}

A MPTT is used for extracting the maximum power from the solar PV module and transferring maximum power from the solar PV module to the load. There are a large number of algorithms which are able to track the MPPs. Some of them are simple such as voltage and current feedback based and some are more complicated such as perturbations and observations $(\mathrm{P} \& \mathrm{O})$ or incremental in conductance method, fuzzy logic method ect.. Having a curious look at the recommended methods will climbing and perturbation and observation $(\mathrm{P} \& \mathrm{O})$ are the algorithm which were in center of consideration because of their simplicity and easy of implementation. Hill climbing is the perturbation in the duty ratio of the power converter and $\mathrm{P} \& \mathrm{O}$ method is perturbation in the operating voltage of the PV array. However $\mathrm{P} \& \mathrm{O}$ algorithm cannot compare array terminal voltage with actual MPP voltage such the change in power is only considered to be a results of the its array terminal voltage perturbation as a result of they are not accurate enough because they piston study steady state oscillation which consequently step size oscillation can be reduced. 


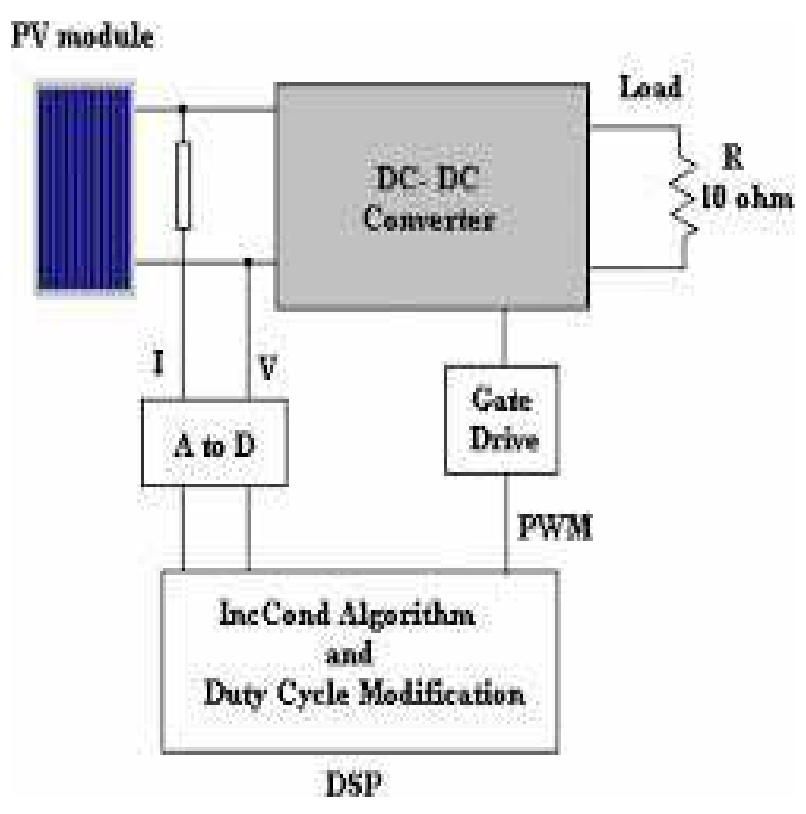

Fig.1 Direct control method used in the MPPT

In this paper two most popular of MPPT technique perturbation and observe $(\mathrm{P} \& \mathrm{O})$ method and incremental conductance method and cuk converter will involve in comparative study. Few comparisons such as voltage, current, power output for each different combination have been recorded. Multi change in duty cycle irradiancy temperature by keeping voltage and current as main sensed parameter will compared by using MATLAB tools simulink .

\section{(B) Incremental Conductance Method}

Incremental conductance (IncCond) is a more elaborate version of the $\mathrm{dp} / \mathrm{dv}$ algorithm because the power equals $\mathrm{v}^{*} \mathrm{I}$, the derivative of power with respect to voltage equals.

Figure $=2$ shows the slope of the PV array power curve is zero at the MPP increasing on the left of MPP and decreasing on the right of MPP. The basic equation of these methods is as fallows.

$\mathrm{dI} / \mathrm{dt}=-\mathrm{I} / \mathrm{V}$ at MPP

$\mathrm{dI} / \mathrm{dt}>-\mathrm{I} / \mathrm{V}$ at left of MPP-

$\mathrm{dI} / \mathrm{dt},<-\mathrm{I} / \mathrm{V}$ at right of MPP----(3)

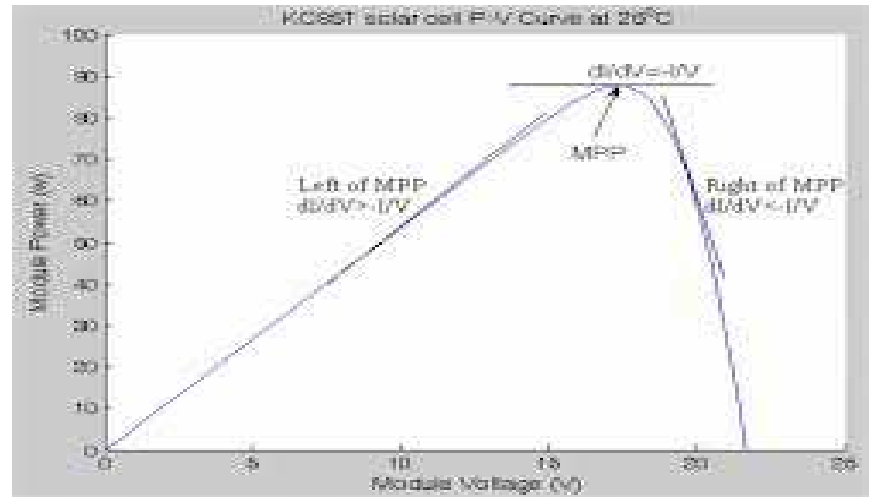

Figure.2

Where I and $\mathrm{v}$ are PV array output current and voltage respectively With the help of these equations The next operating point is chosen. In the above equation are left of MPP equation represent incremental conductance of PV modules and right of equation they represent instantaneous conductance and also from equations (1),(2)\&(3) It is obvious that when the ratio of change in the output conductance is equal to the negative output conductance solar array will operate at the maximum power point.Accuracy of this method proven where it mentions that increasing conductance method can track the true MPPs independent of PV array characteristics. Comparison between $\mathrm{P} \& \mathrm{O}$ and IncCond method with cuk converter and show that efficiency of experiment result up to $95 \%$.in efficiency was observed as much to be as $98.2 \%$.

\section{C).Direct Control Method}

In this paper incremental conductance method with direct control is also selected .The PI control loop is eliminated and duty cycle adjacent directly in the algorithm .a PI controller is an effective way of implementing the IncCond algorithm as an input for this controller an error signal is constructed $\mathrm{E}=\mathrm{dI} / \mathrm{dV}$ $+\mathrm{I} / \mathrm{V}$

Conventional MPPT system has two independent control loops to control MPPT algorithm and second one is usually a P or PI controller. Incremental conductance methods make use of instance nous and incremental conductance to generate an error signal which is zero at MPPT if it is not zero most of the operating point. The main purpose of the second control loops is to make the error from the MPPS near zero.

To compensate the lack of PI controller in the proposed system a small marginal error of 0.002 was allowed. the objective of this paper is to inseminate the second control loop and to show that sophisticated MMPT method do not necessarily obtained the best result but employing them in a simple manner for complicated electron subject is consider necessary there for control action is done useingaDSPIC33f (digital signal processing ). 


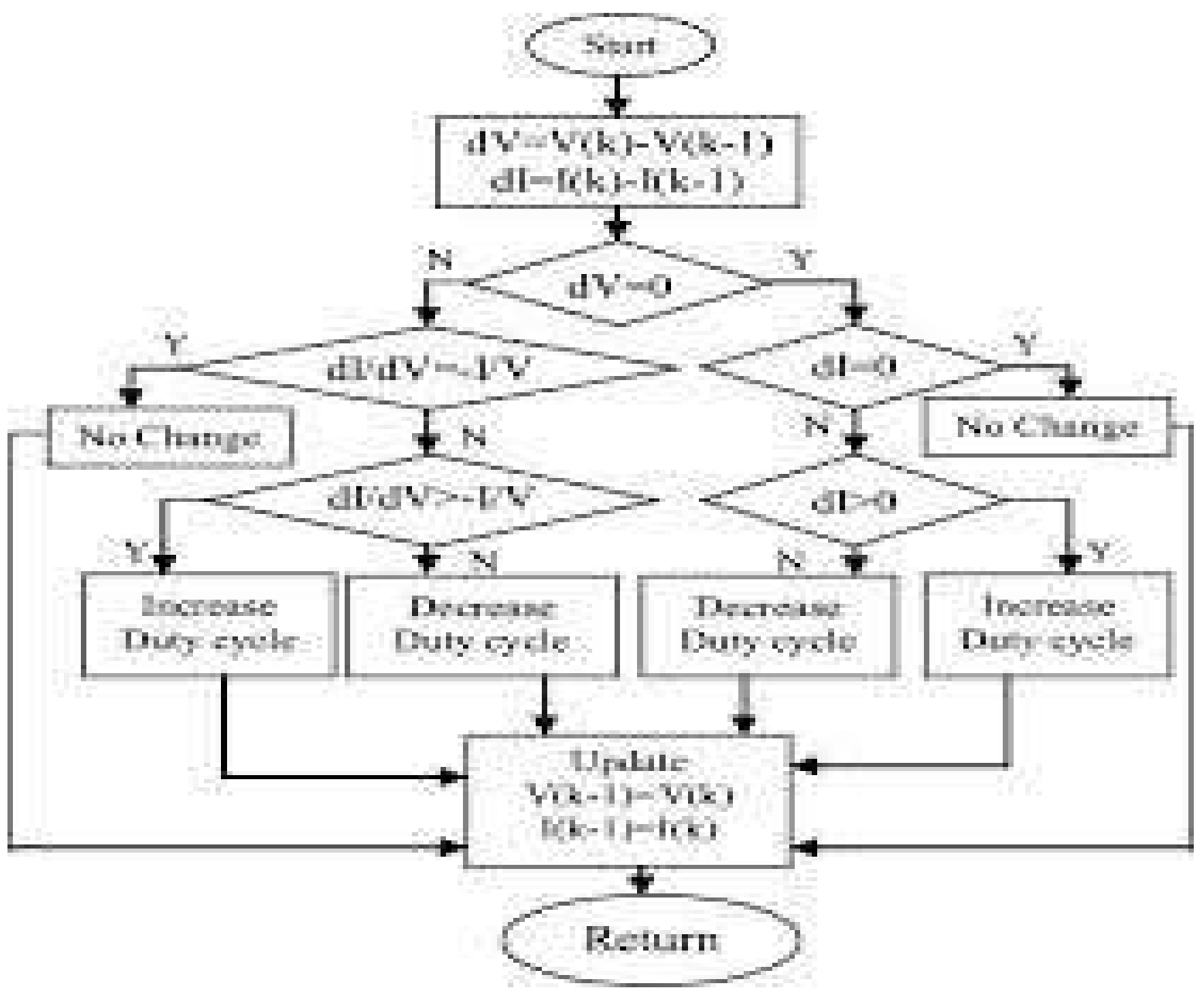

Fig. 3 Flow chart of Incremental conductance with direct control algorithm

Which is specially design for control action it generate pulse width modulation( PWM) wave form to control the duty cycle of the converter switch according to the incremental conductance algorithm .

\section{D).Perturb and Observe (P\&O)}

This perturbation causes the power of the solar module changes if the power increases due to the perturbation thane the perturbation is continued in the derivation after the peak power is reached. The power at next instant decreases and hence after the perturbation reverses. The algorithm is developed in such a manner that it seats references voltage of the module corresponding to the peak voltage of the module. This perturbation causes a new operating point with a different output power incase this output power is larger than previous power this point is set as the new 3 operating point in case it is lower the same power point is adjusted to a lower or higher working voltage depending on the previous step direction. In server studies it has been show that $\mathrm{P} \& \mathrm{O}$ has led to efficiency as high as $96.5 \%$ and $99.5 \%$

\section{PV MODULE AND MPPT}

The structural unit of solar modules is the PV cells. A solar cell converts energy in the photon of sun light in to electricity by means of the photo electric phenomenon found in the certain types semi conductor material such as silicon and selenium a solar panel is basically is a P- N semi conductor junction when exposed to the light to the a dc current is generated current various linearly with solar irradiance. The equivalent electrical circuit of an ideal solar cell can be treated as a current source parallel with a diode. 


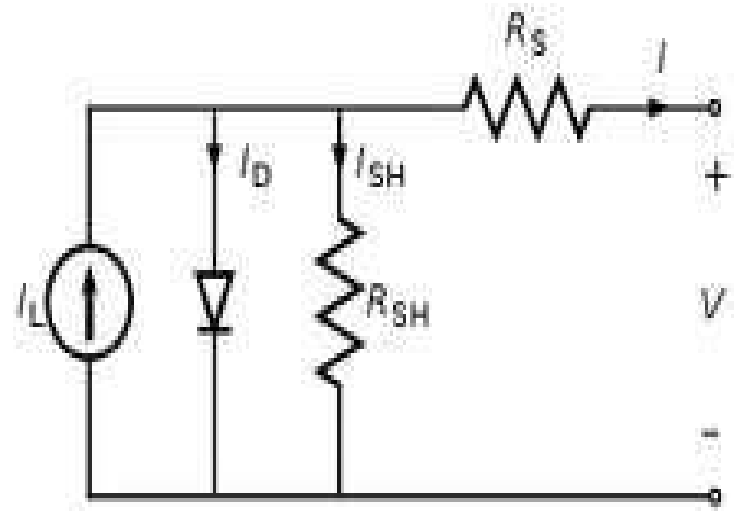

Fig.4 Equivalent electrical circuit of a solar cell

a signal solar can produce a small amount of power to increase the out power of a system, solar cell are generally connected in series or parallel to form PV module .PV module characteristics are comprehensively discuses in which indicate and exponential and non linear dilation between output current and voltage of PV module the main equation for output current of a module Is

$I o=n p I p h-n p I r s[\exp (k 0 v / n s)-1] \ldots$

Where Io is the PV array output current

$\mathrm{V}$ is the PV output voltage

Iph is the cell photo current that is proportional to solar irradiation

Irs is the cell reverence saturations current that mainly depending on the temperature

Ko is a constant

Ns represent number of PV cell connected series

$\mathrm{Np}$ represents number of PV cell connected in parallel.

In cell photo current calculated from

$I p h=[I s c r+(-T r)] S / 100$.

Where:

Iscr is the cell short-circuit current at reference temperature and radiation,

$k i$ is short circuit current temperature coefficient,

$\mathrm{Tr}$ is the cell reference temperature,

$\mathrm{S}$ is solar irradiation in $\mathrm{mW} / \mathrm{cm} 2$.

And cell reverse saturation current is computed from:

$\operatorname{Irs}=(T / T r) 3 \exp ((q E G / k A(1 / \operatorname{Tr}-1 / \mathrm{T})) \ldots(6)$

Where:

$\operatorname{Tr}$ is the cell reference temperature,

Irr is the reverse saturation at ,

$E G$ is the band-gap energy of the semiconductor used in the cell.

For simulations and also experimental setup $\mathrm{KC} 85 \mathrm{~T}$ module was chosen.

\section{ELECTRICAL PARAMETER OF KC85T}

MODULE:

\begin{tabular}{|c|c|}
\hline Maximum power (Pmax) & $87 \mathrm{w}$ \\
\hline Voltage at MPP (Vmpp) & $17.4 \mathrm{v}$ \\
\hline Current at MPP (Impp) & $5.02 \mathrm{~A}$ \\
\hline Open circuit voltage (Voc) & $21.7 \mathrm{v}$ \\
\hline Short circuit current (Isc) & $5.34 \mathrm{~A}$ \\
\hline
\end{tabular}

Electrical parameters are tabulated in table II and the resultant curves are shown in Fig.6 (a) and (b). It shows the effect of varying weather conditions on MPP location at I-V and P-V curves. Fig.5 is current vs. voltage of a PV module. It gives an idea about the significant points on each I-V curve: open circuit voltage, short circuit current and the operating point where the module performs the maximum power (MPP). This point is related to a voltage and current which are Vmpp and Impp respectively and is highly dependent on the solar irradiation and ambient temperature.

In Fig.6, it is clear that maximum power point (MPP) is located at the knee of the I-V curve, where the resistance is equal to the negative of differential resistance:

$V / I=-V / I \ldots \ldots \ldots \ldots \ldots(7)$

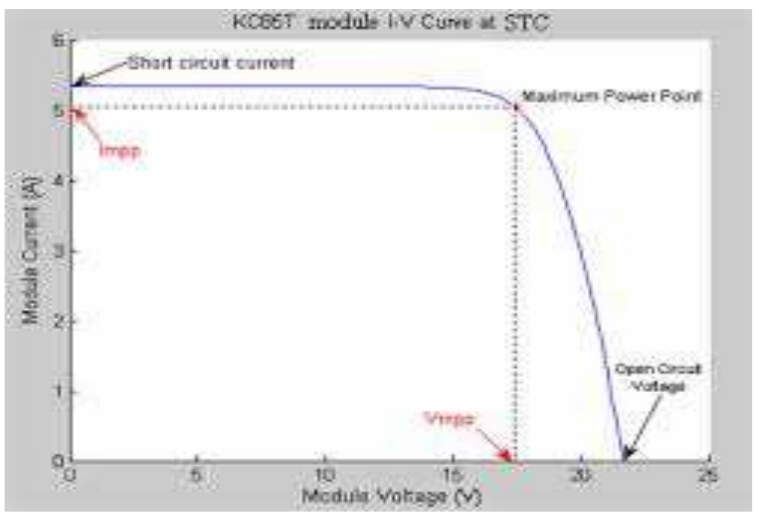

Fig.5 Current-versus-voltage curve of a PV module

This is following the general rule used in the $\mathrm{P} \& \mathrm{O}$ method that the slope of the PV curve at MPP is equal to zero:

$d P / d V=0$

Equation (8) can be rewritten as below:

$d P / d V=I \cdot d V / d V+V \cdot d I / d V$ 
$d P / d V=I+V \cdot d I / d V$

And hence;

$I+V \cdot d I / d V=0$.

Which is the basic idea of the incremental conductance algorithm one noteworthy point to mention is that equation (7) or (8) rarely occurs in practical implementation and a small error is usually permitted. Size of this permissible error (e) determines the sensitivity of the system. This error is selected with respect to the swap between steady state oscillations and risk of fluctuating at a same operating point. It is suggested to choose a small and positive digit . Thus (10) can be rewritten as (12):

$I+V \cdot d I / d V=e$

In this paper value of - e was chosen as 0.002 on the basis of trial and error procedure. The flow chart of the IncCond algorithm within the direct control method is illustrated in Fig. 3. According to the MPPT algorithm, duty cycle (D) is calculated. This is the desired duty cycle that PV module must operate on the next step. Setting new duty cycle in the system is repeated according to the sampling time

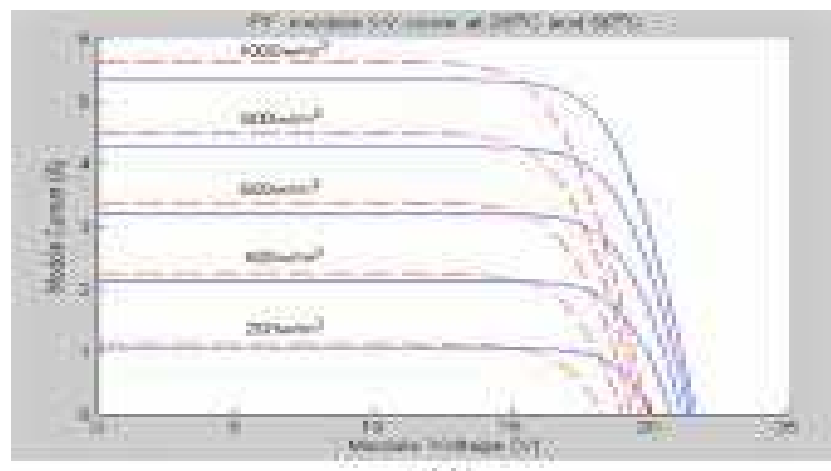

in

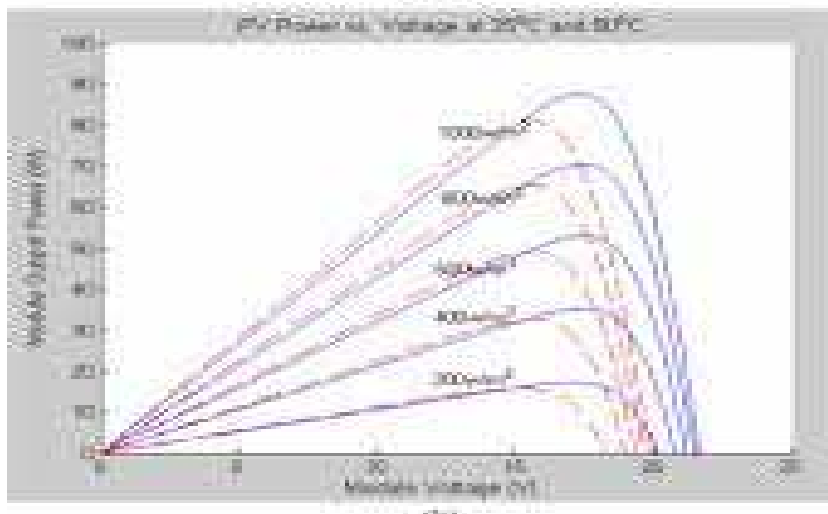

IIII

Fig. 6 Maximum power with varying weather conditions $[-25$ $\left.{ }^{\circ} \mathrm{C},-50{ }^{\circ} \mathrm{C}\right]$. (a) I-V curves. (b) $\mathrm{P}-\mathrm{V}$ curves

\section{SELECTING OF CUK CONVERTER}

Among all the topologies available, both Cuk and buck-boost converters provide the opportunity to have either higher or lower output voltage compared with the input voltage. Although the buck-boost configuration is cheaper than the Cuk one, some disadvantages, such as discontinuous input current, high peak currents in power components, and poor transient response, make it less efficient. On the other hand, the Cuk converter has low switching losses and the highest efficiency among non isolated dc-dc converters. It can also provide a better output-current characteristic due to the inductor on the output stage. Thus, the Cuk configuration is a proper converter to be employed in designing the MPPT.When proposing a maximum power point tracker, the major job is to choose and design a high efficient converter which is supposed to operate as the main part of the MPPT. Efficiency of switch mode DCDC converters is widely discussed in. Most switching mode power supplies (SMPS) are well designed to function with high efficiency. Among all the topologies available, both cuk and buck boost converters provide the opportunity to have either higher or lower output voltage compare with input voltage. Although buck- boost configuration is cheaper than cuk, some disadvantages such as discontinuous input current, high peak currents in power components and poor transient response makes it less efficient. On the other hand, cuk converter has low switching losses and highest efficiency among non-isolated DC-DC converters. It also can provide a better output current characteristic due to the inductor on the output stage. Thus cuk configuration is a proper converter to be employed in designing the MPPT.

Figs. 7 and 8 depicts cuk converter and its operating modes which used as the power stage interface between PV module and the load. Cuk converter has two modes of operation. First mode of operation is

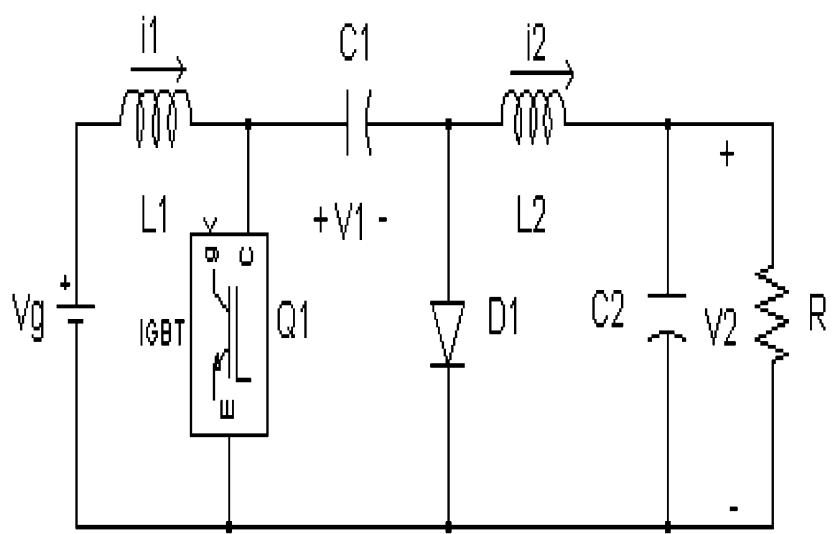

Fig .7 Electrical circuit of the Cuk converter used as the PV power-stage interface 


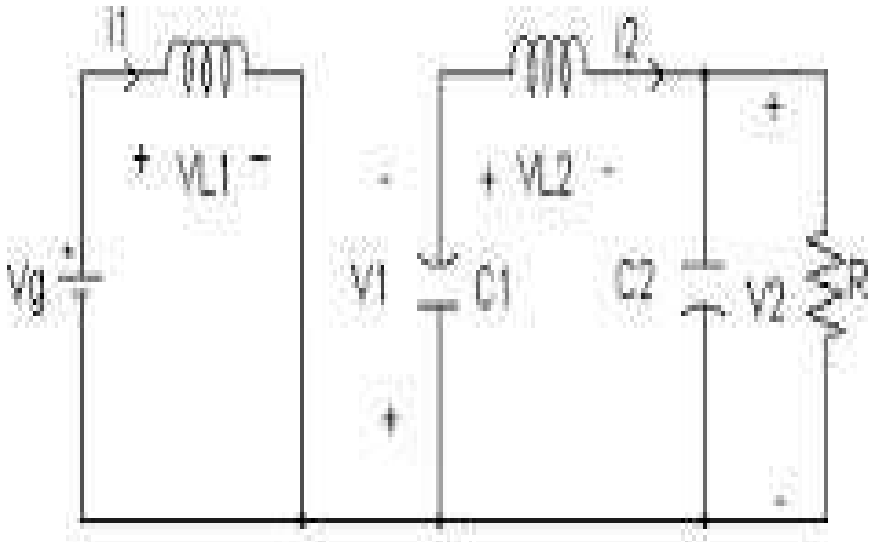

(4)

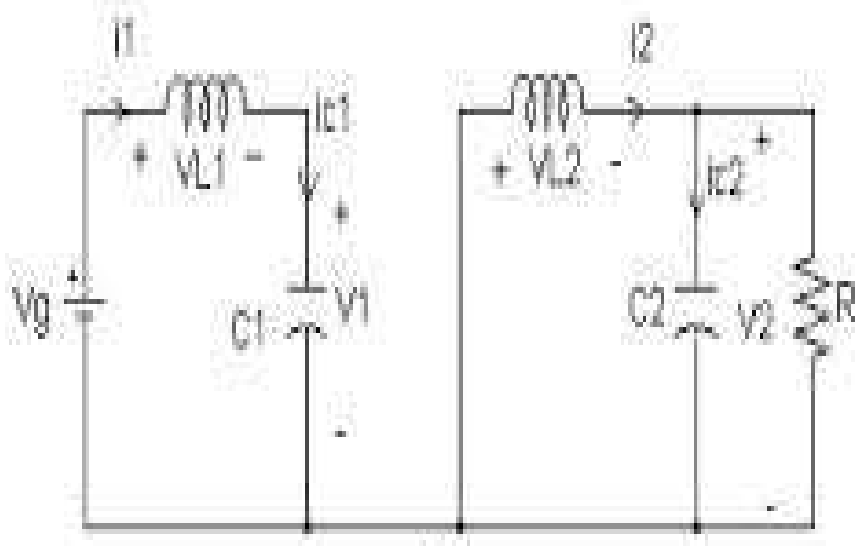

(b)

Fig .8 Cuk converters with (a) switch ON and (b) switch OFF.

When the switch is closed (ON) and it is conducting as a short circuit. In this mode, capacitor releases energy to the output. The equations for the switch conduction mode are as follows:

$v L 1=V g$

$v L 2=-v 1-v 2$

$i c 1=i 2$

$i c 2=i 2-v 2 / R$

On the second operating mode when the switch is open (OFF), diode is forward biased and conducting energy to the output. Capacitor $\mathrm{C} 1$ is charging from input.

Equations for this mode of operation are:

$v L 1=V g-v 1$ $v L 2=-v 2$

$i c 1=i 1$

$i c 2=i 2-v 2 / R$

The principles of cuk converter operating conditions state that the average values of the periodic inductor voltage and capacitor current waveforms are zero, when the converter operates in steady state. Relations between output and input currents and voltages are given in (21) and (22).

Vo $/$ Vin $=-D /(1-D)--------(21)$

$\operatorname{Iin} / \operatorname{Io}=-D /(1-D)$

Some analysis of cuk converter specifications are provided in and a comparative study on different schemes of switching converters is presented in the literature. Components for the cuk converter used in simulation and hardware setup were selected as follows:

Input inductor L1 $=5 \mathrm{mH}$;

Capacitor C1 (PV side) = 47 $\mu$;

Filter inductor L2 $=5 \mathrm{mH}$;

Switch: $\quad$ IGBT (IRG4PH50U);

Freewheeling diode: RHRG30120;

Capacitor C2 (filter side) $=1 \mu \mathrm{f}$;

Resistive load $=10 \Omega$;

Switching frequency $=10 \mathrm{kHz}$;

Controller: TMS320F2812 DSP.

\section{Components for Measurement Circuit:}

Voltage Transducer: LV25-P;

Current Transducer: LA25-NP.

The power circuit of the proposed system consists of a Cuk converter and gate drive, the control of the switching is done using the control circuit. The control tasks involve measuring analog voltage and current of the PV module using current and voltage sensors, convert them to digital using ADC, process the obtained information in a microcontroller and then compare to the predefined values to determine the next step, revert the PWM to the gate drive and hence control the switching of IGBTs. The control loop frequently happens with respect to the sampling time and the main program continues to track the MPPs.

\section{SIMULATION RESULTS}

Diagram of the closed loop system designed in Matlab/Simulink is presented in Fig.10 that includes the PV module electrical circuit, cuk converter and the MPPT algorithm. Converter 


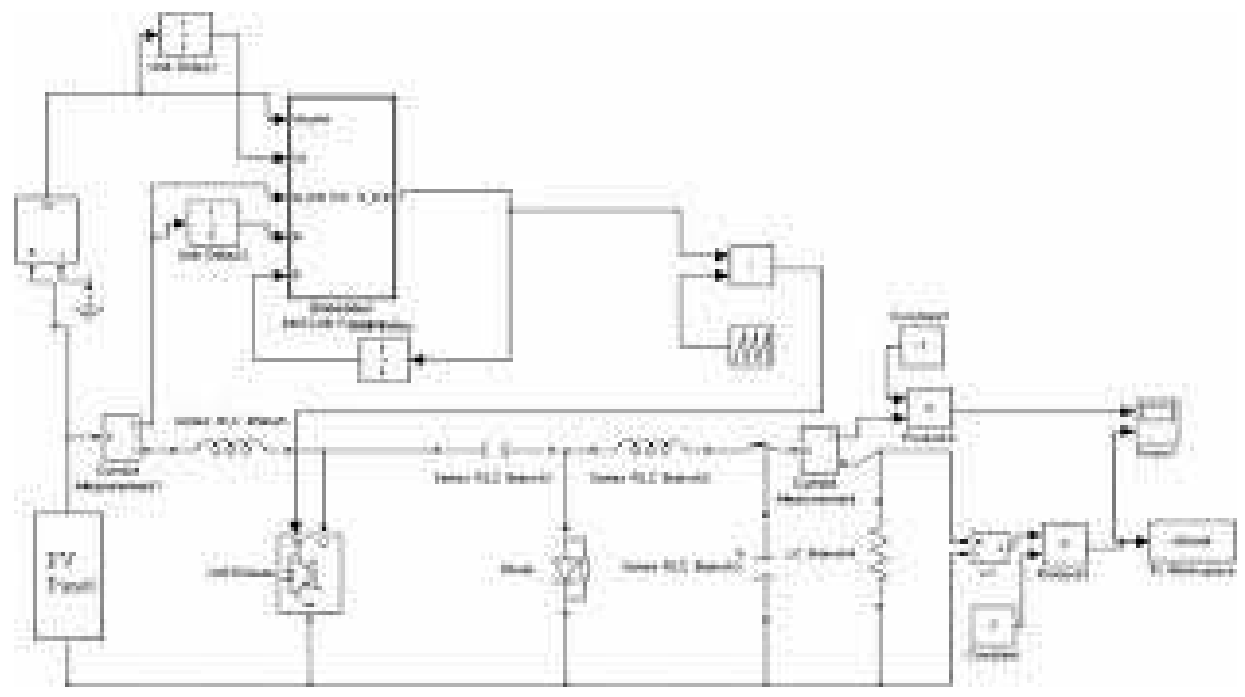

Fig.10 Diagram of the closed-loop system.

Components are chosen according to the values presented in section II. The PV module is modeled using electrical characteristics to provide output current and voltage of the PV module. The provided current and voltage are fed to the converter and the controller simultaneously.

The PI control loop is eliminated and the duty cycle is be adjusted directly in the algorithm.

To compensate the lack of PI controller in the proposed system a small marginal error of 0.002 is allowed.To test the system operation, conditions of changing irradiation was modeled.

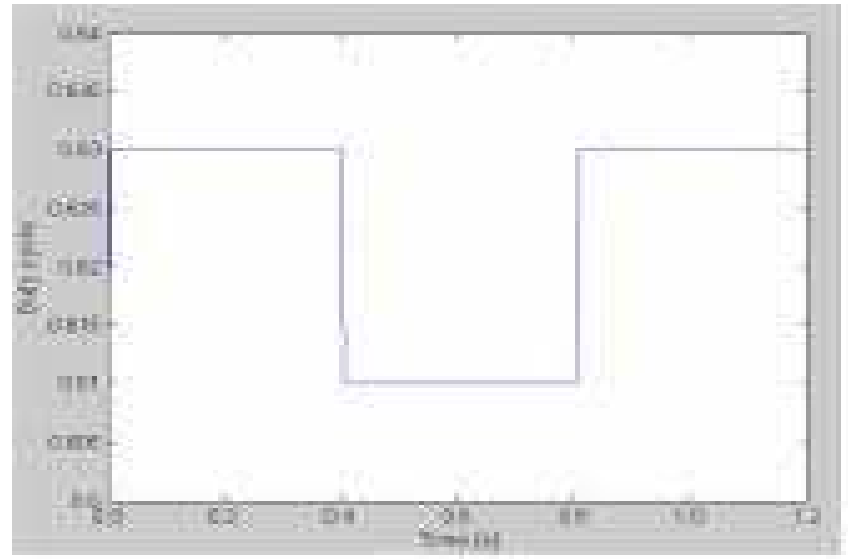

II
Temperature is constant at $25^{\circ} \mathrm{C}$ and the illumination level is varying between two levels. First illumination level is $1000 \mathrm{w} / \mathrm{m}^{2}$; at $\mathrm{t}=0.4 \mathrm{~s}$ illumination level suddenly changes to $400 \mathrm{w} / \mathrm{m}^{2}$ and then back to $1000 \mathrm{w} / \mathrm{m}^{2}$ at $\mathrm{t}=0.8 \mathrm{~s}$. An illustration of the relationship between the duty cycle and PV output power is presented in Figs. 9 (a) and (b) to demonstrate the effectiveness of the algorithm mentioned in the flowchart. Fig.9 (a) shows the change in duty cycle adjusted by MPPT to extract maximum power from the module.

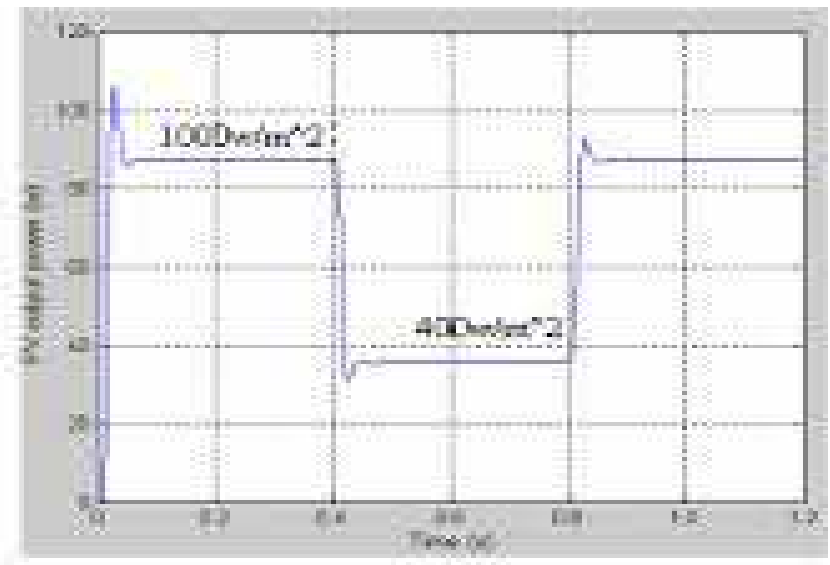

atil

Fig .9 Change in (a) duty cycle and (b) power of the system due to the change in illumination level

The results in Fig.9 (b) demonstrate output power at $\mathrm{G}=1000 \mathrm{w} / \mathrm{m}^{2}$ and $400 \mathrm{w} / \mathrm{m}^{2}$ are $87 \mathrm{w}$ and $35 \mathrm{w}$ respectively which are absolutely the desired output power from Fig.6(b). It also shows that the system provides the best desirable tradeoff between the two irradiation levels. 


\section{EXPERIMENTAL SETUP}

To verify the functionality and performance of proposed system shown in Fig.10, a prototype of cuk converter and control circuit was implemented. TMS320F2812 DSP used to provide the control signals for the cuk converter. $\mathrm{C}$ code of the IncCond algorithm and PWM scheme is built, debugged and run with the help of the DSP development tool, Code Composer Studio (CCS) software. Voltage measurement is required at the point where the PV module output is connected to the input of cuk converter. The voltage at this point is the operating voltage of the PV module. On the other hand, current measurement is also necessary to indicate the generated current of the PV module on each operating point. It is particularly important to determinate the atmospheric condition which is vital in connection with accuracy of MPP tracking. For above mentioned reason, the PV array voltage and current are measured using Hall Effect sensors which were pointed out in section II. But since DSP board cannot tolerate more than $3.3 \mathrm{v}$, the measured values will be scaled down to be compatible with DSP voltage rating. PV array is operating around open circuit voltage $(80 \mathrm{v})$ before connecting the PV to the load through the MPPT circuit. When the PV is connected to the MPPT circuit it does not operate at the mentioned voltage anymore and voltage drops to a new point instantly. This new operating voltage depends on the impedance of the load. In order to move the new operating point to the MPP, control rules of IncCond within direct control loop will assume the function. Solar modules are usually connected together to attain high output power. There are two general types of connecting modules: series and parallel. The type of connection totally depends on the application where large current or voltage is required. The purpose in the series configuration is to increase the output voltage while the parallel connection is made to increase the current. The interconnection of cells in a module itself is mostly in series to provide higher voltage. When modules are connected in series, the total voltage is the sum of each module voltage but the current stays constant and it is the smallest current of a module available in the configuration. In the hardware configuration there are 4 modules connected in series. Fig. 1 is illustrating the block diagram of MPPT system with direct control using cuk converter. Sampling time of the system is chosen to be $0.2 \mathrm{~s}$, which is the required time for the designed cuk converter to reach the steady state condition. The step size of duty cycle is chosen to be 0.2 so the converter can smoothly track the MPP. Fig. 10 shows the initial waveforms of current and voltage after connecting the PV module to the circuit. There is some overshoot in both waveforms which was predicted from simulation results in Fig.8 (b). Having a depth investigation on system performance under rapidly varying illumination levels, the numbers of the modules were changed from 3 to 2 modules. Variation of voltage and power of the system are shown in Figs. 11 and 12, respectively. Fig.13 denotes the voltage of the PV for decreasing the irradiation level and thereafter increasing it. It shows dynamic performance of the system.

\section{CONCLUSIONS}

In this manuscript fixed step size IncCond MPPT with direct control method was employed while the necessity of another control loop is eliminated. The proposed system was simulated and constructed, and the functionality of suggested control concept was proven. From the results acquired during the simulations and hardware experiments, it was confirmed that with a well designed system including a proper converter and selecting an efficient proven algorithm, implementation of MPPT is simple and can be easily constructed to achieve an acceptable efficiency level of the PV modules.

The results also indicate that the proposed control system is capable of tracking the PV array maximum power, and thus improves the efficiency of PV system, reduce one part a accounts, low power loss and system cost.

\section{REFERENCES:}

[1] N. Femia, D. Granozio, G. Petrone, G. Spagnuolo, and M. Vitelli, "Predictive \& adaptive MPPT perturb and observe method," IEEE Trans. Aerosp. Electron. Syst., vol. 43, no. 3, pp. 934-950, Jul. 2007.

[2] E. Koutroulis, K. Kalaitzakis, and N. C. Voulgaris, "Development of a microcontroller- based, photovoltaic maximum power point tracking control system," IEEE Trans. Power Electron., vol. 16, no. 1, pp. 46-54, Jan. 2001.Pandey, N. Dasgupta, and A. K. Muk erjee, "Design issues in implementing MPPT for improved tracking and dynamic performance," in Proc. 32nd IECON, Nov. 2006, pp. 4387-4391.

[3] K. H. Hussein, I. Muta, T. Hoshino, and M. Osakada, "Maximum photovoltaic power tracking: An algorithm for rapidly changing atmospheric conditions," Proc. Inst. Elect. Eng.-Gener., Transmiss.Distrib., vol

[4] Zhou Yan, Liu Fei, Yin Jinjun, Duan Shanxu, - Study on realizing MPPT by improved incremental conductancemethod with variable step-sizell ICIEA, IEEE Conference on Industrial Electronics and applications, pp. 547 550, June 2008

[5] Fangrui Liu, Shanxi Duan, Fei Liu, Bangyin Liu, and Yong Kang, - A variable step size INC MPPT method for PV systems\|, IEEE Trans. on Industrial Electronics, vol. 55, no. 7, pp.2622 2628, July 2008

[6] Francisco M. González-Longatt, -Model of photovoltaic module in Matlab ${ }^{\mathrm{TM}}, \|$ 2do congreso iberoamericano de estudiantes de ingeniería eléctrica, electrónica ycomputación, ii cibelec 2005.

[7] Trishan Esram, Patrick L. Chapman, -Comparison of Photovoltaic Array Maximum Power Point Tracking Techniques\| IEEE Trans. on Energy Conversion, vol. 22,no. 2, pp.439-449, June 2007.

[8] V. Salas, E. Olias, A. Barrado, and A. Lazaro, -Review of the maximum power point tracking algorithms for standalone photovoltaic systems, $\|$ Sol. Energy Mater. Sol. Cells,vol. 90, no. 11, pp. 1555-1578, Jul. 2006. 